\title{
EL CENTRO ALFARERO DE JIMÉNEZ DE JAMUZ. ESTUDIO HISTÓRICO Y ETNO-ARQUEOLÓGICO
}

\author{
Raquel MARTÍNEZ PEÑíN \\ Universidad de León
}

\begin{abstract}
RESUMEN: El objetivo de este artículo es presenta una estimación de las posibilidades que ofrecen tanto las fuentes documentales como etno-arqueológicas para el análisis de la actividad alfarera de Jiménez de Jamuz. Este trabajo incide sobre todo en aspectos técnicos y en la organización social de este oficio.
\end{abstract}

PALABRAS CLAVE: etno-arqueología, actividad alfarera, Jiménez de Jamuz.

ABSTRACT: The aim of this article is to show an outcome of the posibilities gives, taking into not only those from the documents, but also from the ethno-archaeology to examine the pottery from Jiménez de Jamuz. This work stresses overcoat technical aspectes and the organitation of this trade.

KEYWORDS: athno-archaeology, Jiménez de Jamuz.

\section{INTRODUCCIÓN.}

La producción cerámica de Jiménez de Jamuz cuenta con una serie de estudios etnográficos de los que los más recientes ofrecen una información que, aunque parcial, resulta básica para poder afrontar un estudio histórico y etno-arqueológico de la actividad artesanal desarrollada en esta población ${ }^{1}$.

Los estudios de documentación sobre cerámica se han limitado a recoger las noticias referidas a los alfareros de Jiménez de Jamuz en el Catastro del Marqués de Ensenada de $1752^{2}$ conservado en el Archivo Histórico Provincial de León.

${ }^{1}$ KOPER, W. (1981). Guía de los alfares de España. Madrid: Editora Nacional. BRANDO CAstillo, M. \& GonzÁlez ArPide, J. L. (1990). Alfarería popular leonesa. León.

21 A.H.P.L. Catastro de Ensenada, Respuestas Generales al cuestionario del marqués de Ensenada. Señorio de conde Luna: Jiménez de Jamuz. Rollo número 105, legajo 430. 
Al mismo tiempo, tampoco contamos con estudios de carácter etnoarqueológico que permitan conocer las diferentes instalaciones y métodos de trabajo, que al menos desde la Edad Moderna, se vienen desarrollando en este pueblo alfarero.

En consecuencia, trataremos de afrontar de manera sistemática un estudio histórico y etno-arqueológico de este artesanado. Por un lado, intentamos abordar las posibilidades que ofrecen fuentes documentales como los censos, testamentos e inventarios post mortem y por otro, las aportaciones debidas a la etno-arqueología.

\section{LOCALIZACIÓN ESPACIAL Y TEMPORAL.}

El pueblo de Jiménez de Jamuz se sitúa a unos 53 kilómetros al W. de la ciudad de León y en la actualidad cuenta con una población de aproximadamente 1.000 habitantes (Fig. 1).

A lo largo de la Edad Media este pequeño municipio formaba parte de los bienes que conformaban el señorío de Valdejamuz.

En el siglo XII pasa a constituirse como parte del territorio que el linaje de los Vermúdez poseía en el Reino de León y, un siglo después, fue transferido al de los Morales.

Hacia 1370 el concejo de Valdejamuz se integra en el señorío de los Quiñónez de la mano del que fuera Adelantado Mayor de León y de Asturias, Pedro Suárez (13467-1402).

En el año 1442, el monarca Juan II concede a Diego Fernández de Quiñónez I (1438-1484) la potestad de fundar mayorazgo, y lo hace en las personas de sus cuatro hijos varones. En consecuencia, el concejo de Valdejamuz pasa en mayorazgo a Suero Quiñónez I (1409/10-1458).

A finales del siglo XV, se inicia un largo pleito entre la Casa de Luna y los señores de Valdejamuz que termina en el año 1590 y con la muerte sin descendencia de Suero Quiñónez II (1517/20-1590), de modo que los bienes del mayorazgo pasaron íntegramente a los condes de Luna ${ }^{3}$.

Durante toda la Edad Moderna el concejo de Valdejamuz conforma parte de los dominios y rentas de los condes de Luna, hasta que a finales del siglo XIX la

3 Álvarez Álvarez, C. (1997). Los Quiñónez, señores de Valdejamuz (1435-1590). Astorga: Centro de Estudios Astorganos "Marcelo Macías". 
abolición del Régimen Señorial suponga la transformación de las formas de organización política y la aparición de un marco administrativo constituido en torno a los ayuntamientos y pedanías. A partir de este momento, el municipio de Santa Elena de Jamuz se sitúa al frente del concejo, mientras que la población de Jiménez de Jamuz pasa a articularse como simple pedanía ${ }^{4}$.

\section{ESTUDIO DOCUMENTAL.}

Las fuentes de carácter fiscal resultan de gran utilidad a la hora de afrontar el estudio documental de este centro de producción: en los censos, junto al cabeza al cabeza de familia se cita en ocasiones el oficio que estos desarrollan, de tal forma que puede confirmarse la presencia de alfareros en esta localidad en la fecha de realización del censo. Para el caso de Jiménez de Jamuz disponemos de una serie de censos a los que podemos referirnos.

El censo de Castilla de $1591^{5}$ recoge el número de vecinos que residían en esta población en tiempos del rey Felipe II y en él figuran los diferentes estamentos sociales en los que se integra cada uno, sin que proporcione información de la actividad practicada por los mismos.

Sin duda, la fuente documental que, hasta el momento, ha resultado más útil en nuestro estudio son las Respuestas Generales al Catastro del Marqués de Ensenada del año $1752^{1}$. En éstas, junto al cabeza de familia, se menciona el oficio al que se dedica, de tal forma que se documenta la presencia en Jiménez de 41 alfareros en el año en que se realizó el asiento.

El censo de Aranda de $1768^{6}$ ofrece un recuento general de trescientos once vecinos en la localidad, aunque sin llegar a concretare la actividad desarrollada por éstos.

En el censo de Floridablanca de $1787^{7}$, Jiménez de Jamuz cuenta con trescientos trece habitantes; veinte de éstos artesanos y veintitrés jornaleros, lo que nos lleva a creer que una parte de ambos grupos se dedican a este oficio bien como maestros alfareros bien como asalariados.

${ }^{4}$ RUBio PÉREZ, L. M. (1993). El sistema político concejil en la provincia de León. León: Universidad de León, p. 115.

${ }^{5}$ Censo de Castilla de 1591: "Vecindarios". Madrid, 1984: 325.

${ }^{6}$ B.R.H: Censo de Aranda (Obispado de Astorga).

${ }^{7}$ Censo de "Floridablanca". Submeseta norte: parte occidental. T.B.3. Madrid, 1986: 3171 
Además, resulta de interés la consulta de algunos de los antiguos diccionarios geográficos que incluyen el ámbito leonés. En éstos se mencionan algunas de las actividades económicas e industriales desarrolladas en las diferentes localidades; en el caso de Jiménez de Jamuz destaca la alfarería, lo que hace suponer la importancia que este artesanado llegó a alcanzar en el siglo XIX.

Entre los diccionarios referidos destaca el Diccionario geográfico-estadístico de Esapaña y Portugal obra de Sebastián Miñano y Bedoya ${ }^{8}$ (1826) que se refiere a la actividad industrial alfarera desarrollada en el municipio:

“... Industria: alfarería de que surten todo este pais hasta Leon... .”.

También se hace mención a este oficio en la compilación de lugares que Pascual Madoz lleva acabo en su Diccionario geográfico-estadístico-histórico de 1850":

“.... IND.: alfareria de que preveen á casi todos los pueblos de la comarca hasta Leon, telares de lienzos ordinarios y algun molino harinero".

Al mismo tiempo, aludiremos, entre la documentación de carácter privado, a los inventarios post mortem de bienes de alfareros conservados en el Archivo Histórico Provincial de León, que ofrecen la posibilidad de ahondar en su espacio privado. Los útiles enumerados en este tipo de inventarios proporcionan una buena base para conocer el entorno físico en el que se desarrollaba esta actividad. Entre los inventarios examinados, hemos escogido por su minuciosidad con respecto al tema que nos ocupa uno del año 1789 referido al alfarero de Jiménez de Jamuz, Bartolomé Cabañas ${ }^{10}$.

Tras la muerte de Bartolomé Cabañas, su viuda e hijos encargaron el inventario y tasación de los bienes habidos en la casa-taller que el difunto poseía en el casco urbano del municipio. En el inventario se cuantifican algunos objetos imprescindibles en el trabajo de alfarero como son: aperos (carro, carretas, cribas, azada) y animales de tiro (bueyes y vacas de labranza); objetos utilizados para pastar la arcilla (rastrillo, pala metálica); carros y carretas para transportar el barro desde la zona de extracción; cribas para tamizar la arcilla; una rueda para modelar con un disco superior de repuesto (cabezuela); tablas de oficio en las que se

${ }^{8}$ Miñano y Bedoya, (1826): Diccionario geográfico-estadístico de España y Portugal dedicado al Rey nuestro señor. Tomo V. Madrid, p. 105.

${ }^{9}$ MadOZ, P. (1925). Diccionario geográfico-estadístico-histórico: León. Tomo III. Valladolid: Ediciones Ámbito, p. 126.

${ }^{10}$ A.H.P.L. Protocolos Notariales. Caja 7601, folios 3-20. 
disponían las piezas fabricadas; una pala de hierro (tornadera) usada en la carga de combustible del horno; una escalera de mano utilizada para observar el proceso de cocción; un conjunto de piezas cerámicas; serones de mimbre en los que se disponía la vajilla una vez cocida; cargas en las que se llevaban los productos a los destinos de venta.

Por otra parte, el registro cita no sólo la situación que tiene la casa-taller en el municipio sino que también detalla algunas de sus estancias. La narración comienza con una cocina-obrador con chimenea donde discurre tanto la vida doméstica como la laboral; una habitación que alberga el horno de cocer cerámica y una dependencia aneja a la vivienda, con su panera y corredor. En la parte delantera de la casa se abrían un patio, con portal cubierto de teja, en el que se guardaba el combustible del horno, y unas puertas de calle por las que se accedía a la casa. Además, la parte trasera disponía de un segundo corral con puertas grandes de carro a través de las que entraban y salían los carros y carretas.

Para finalizar, en el inventario se señalan las heredades de Bartolomé Cabañas en el municipio de Jiménez de Jamuz: entre las tierras de labor se menciona un linar (linar del Cad de Abajo) en el que el artesano conseguía parte del combustible para el horno, además de algunas parcelas de extracción de arcilla (Barreros de Valdepiertigas, La Barrerina...), con una toponimia fosilizada, pero que se refiere a la actividad aquí desarrollada.

\section{ESTUDIO DE LA ACTIVIDAD ALFARERA.}

La finalidad de este estudio es llegar a establecer una conjunto de analogías entre la producción alfarera que, al menos desde el siglo XVII y hasta los años 70 del siglo pasado, se venía desarrollando en esta población y de este modo poder explicar los comportamientos del pasado en lo que concierne a esta actividad artesanal. Nuestro análisis tiene en cuenta tanto las características del proceso tecnológico de fabricación de cerámica a torno como el instrumental necesario para dicha actividad.

Los datos proceden de las labores de campo desarrolladas a lo largo de los meses de otoño e invierno del año 2005, para lo cual observamos directamente la actividad diario de algunos de los ceramistas que aún mantienen esta técnica de trabajo. Para obtener información sobre este oficio en el pasado elaboramos una serie de cuestionarios realizados a los alfareros ancianos y los que, todavía hoy, continúan dedicados a esta profesión. 


\subsection{La producción cerámica.}

En la alfarería de Jiménez de Jamuz hemos de diferenciar las labores desempeñadas por los maestros alfareros que obtienen el barro, modelan las cerámicas y las cuecen, de las tareas que se dejan tanto en manos de los aprendices, habitualmente hijos de estos, como de las mujeres, que participaba en la extracción de la materia prima, acondicionan la arcilla, colocan a secar los recipientes cerámicos, ayudan al alfarero en la carga y descarga de la cocción y ornamentan las piezas.

\subsubsection{Obtención de la materia prima.}

El pueblo alfarero de Jiménez de Jamuz se localiza en torno a un yacimiento de arcilla a cielo abierto propiedad de los alfareros (Los Barreros) y a un monte (Casas Viejas) donde es relativamente fácil conseguir combustible para la cocción del horno. La arcilla presenta un alto contenido en hierro, con tono rojizo y de gran plasticidad $^{11}$.

Estos artesanos, junto con aprendices y mujeres, excavan en Los Barreros auxiliados con azadas, picos y palas, cocina-obrador siguiendo la veta de arcilla. Días antes de la extracción, era habitual realizar catas en el yacimiento hasta llegar a la arcilla de mejor calidad. Seguidamente, el alfarero elimina el nivel estéril ( reblo), de casi un metro de espesor. La arcilla obtenida bien se traslada en carros y carretas arrastrados por animales de tiro hasta la casa-taller, bien se extiende y orea en una pequeña parcela (tendales) preparada al efecto en el barrero.

La extracción de la materia prima suele realizarse a lo largo de los meses de primavera y verano, recogiendo la cantidad necesaria para todo el año.

\subsubsection{Preparación de la pasta cerámica.}

Las mujeres desbrozan, allanan y limpian la arcilla en una pequeña superficie (tendales) ubicada bien en la zona de extracción (barreros) bien en el corral de la casa-taller, donde se deja durante unos días para que se oree. Una vez que ha perdido parte de la humedad, se guarda en una pequeña estancia (toña) próxima a la cocina-obrador, donde termina de secarse.

En algunos casos, la preparación de la masa arcillosa comienza con la limpieza y depurado de la materia prima: el barro, una vez triturado, se criba con el fin de aislar las impurezas que puedan quedarle. La arcilla triturada se sumerge en una

${ }^{11}$ Alonso Herrero, E. (2004). Guía geológica visual de León. León: Celarayn editorial. 
balsa llena de agua (barrera) y se remueve con la ayuda de una pala fabricada en madera de roble (batedera). En esta fase del proceso, es habitual mezclar arcillas de distinta calidad con el fin de obtener una mezcla adecuada al tipo de recipiente que se quiere tornear. Lo más habitual es dejar el barro unas horas en remojo o bien mantenerlo debajo del agua veinticuatro horas para que adquiera la consistencia adecuado.

Las pilas en las que se sumerge la arcilla las hemos localizado siempre dentro de la cocina-obrador; éstas son pequeños estanques construidos sobre el suelo y de 1 metro de alto, donde se bate el barro.

Después se traslada a la mesa de sobar, donde se le da la homogeneidad y plasticidad requerida para ser modelado. En el caso de que la pasta cerámica contenga escaso de humedad, el artesano la extiende en el suelo de la cocinaobrador para que el suelo absorba parte del agua, o bien añade a la pasta barro cribado y seco hasta llegar a conseguir el grado de humedad requerido. El amasado o sobado se realiza maleando repetidamente con las manos la arcilla contra la mesa de sobar, dividiéndola en porciones que vuelven a unirse por presión. Al mismo tiempo se elimina todo tipo de impurezas que puedan quedar en la pasta.

El alfarero mezcla diferentes pasta cerámicas en función de la vajilla que vaya a fabricar; así para las piezas destinadas a usos culinarios, como cazuelas, ollas, etc., se incluye arena de cuarzo de grano grueso con objeto de procurarles una mayor resistencia a los cambios térmicos a los que se van a ver sometidas. En cambio, las piezas con un barniz plumbífero, presentan una pasta de tono rojizo, muy depurada y sin apenas impurezas.

Tras el sobado, el barro se coloca en pellas de forma troncocónica, cerca de la rueda del alfarero donde se deja reposar durante unas horas; entonces se amasará de nuevo, aunque ahora sólo la cantidad necesaria para la labor diaria.

\subsubsection{Modelado.}

En la cocina-obrador, de planta rectangular, la rueda o torno se dispone en uno de los laterales colocada contra la pared. La rueda, construida en madera de roble, cuenta con dos discos horizontales paralelos (cabezuelas) unidos por un eje vertical enterrado en el suelo. La cabezuela inferior, con un radio de 50 centímetros y dispuesta a unos 10 centímetro del firme, es la receptora de la fuerza generada por el pie del alfarero. La cabezuela superior, con un radio de 15 centímetros, sobre la que el artesano coloca y centra el bolo para tornearlo con las dos manos. Las dos cabezuelas distan entre sí aproximadamente un medro. El eje del torno se sustenta por medio de un tronco cilíndrico con una perforación central en la que se ancla, al 
mismo tiempo que va hundido en una cavidad de unos 10 centímetros de profundidad excavada en el suelo.

El alfarero trabajo sentado en la rueda y de espaldas a la pared. La rueda se coloca en una mesa de tres tablas donde se dispone la pella de arcilla y los instrumentos requeridos para el modelado. Esta mesa cuenta con un espacio apropiado para situar las tablas de oficio, de unos 2,5 metros de largo y 30 centímetros de anchura, utilizadas para trasladar las piezas recién torneadas al lugar de secado. Un travesaño horizontal apuntala la mesa a la pared, mientras que una tabla aneja al muro y dispuesta a la misma altura que la cabezuela superior es usada como asiento.

De esta forma, el artesano hace girar la cabezuela inferior con el pie derecho, transmitiendo de este modo un movimiento centrífugo a la cabezuela superior. En la mesa se colocan los útiles necesarios para el tornedo: la pella, con un grado de humedad idóneo para el modelado, se sitúa a la derecha del alfarero, junto a un recipiente que contiene el agua necesaria para que el alfarero pueda sumergir en ella las manos y así evitar que el barro se pegue a ellas.

El torneado consiste en: por medio de golpes secos el artesano amasa el barro con las manos, centra el bolo en la cabezuela superior y lo abre ejerciendo cierta presión con los pulgares, con el puño cerrado y el pulgar saliente, introduce la mano derecha para comenzar a subir la arcilla al tiempo que la presiona para lograr el espesor y tamaño deseado. Tanto el cuello y borde como el labio del recipiente se suavizan con la pieza de cuero o tiradera y con el recorteador quitan las rebabas y se cierras los poros de la cara exterior. La vajilla se decora en el torno cuando se trata de una ornamentación incisa, logra mediante un recorte de madera con uno de lo extremos en punta (punta de embocar), o de digitaciones. Una vez modelada, la pieza se separa de la cabezuela superior, introduciendo a ras del disco, un alambre, y se dispone en la tabla de oficio.

En la fabricación de cerámicas de grandes dimensiones (tinajas, lebrillos, etc.), el alfarero pone sobre la cabezuela superior una placa circula de madera (cabezuela) sobre la que se tornean estos recipientes.

\subsubsection{Secado parcial de la cerámica.}

Tras un secado parcial de la pieza (dureza del cuero) durante dos horas, se procede a colocar las partes que no es posible modelar en la rueda (enasado, embocado). Para añadir asa, picos vertedores, etc. se requiere un barro de gran plasticidad por lo que se reutiliza el sobrante del torneado (ralillas). 
En este estado, la arcilla cuenta con el grado de humedad y dureza adecuada para eliminar los restos de barro que pueden haber quedado de modelado (rebabas) y pulir las bases (repasar la pieza) con la ayuda de una espátula de madera (recorteador).

\subsubsection{Secado total.}

Antes de proceder a la cocción, es imprescindible eliminar el agua que aún pueda contener la pasta cerámica, el secado se inicia en el corral de la casa-taller y finaliza en la cocina-obrador. El secado por evaporación se realiza de modo progresivo con el fin de evitar agrietamientos en la pieza, por este motivo el alfarero procura que durante las primeras horas de secado las piezas no se vean sometida a la acción directa de aire y sol.

\subsubsection{Decoración.}

Las piezas cerámicas se ornamentan tanto con incisiones, aplicaciones de cordones, digitaciones o estampaciones, que se efectúan durante el primero de los secados, como pintadas realizadas con óxido cálcico (cal morena) disuelto en agua, aplicado a la vajilla aún cruda y previamente al vidriado, utilizando para ello pinceles o plumas de gallina.

Las piezas vidriadas son impermeabilizadas con un vedrío plúmbeo conseguido mediante una suspensión acuosa. El barnizado se realiza (bañar las piezas) bien por inmersión bien derramando el vedrío en su superficie exterior o interior.

Este barniz está compuesto por Sulfuro de Plomo que los alfareros denominan alcohol de hoja, adquirido en las minas de galena que se explotaban en Linares (Jaén). Este llega en terrones que las mujeres trituran con un molino de mano, para más tarde mezclarlo con agua (envuelta) y tamizarlo.

Las mujeres, antes de la cocción, decoran con barniz la cerámica, en barreños de barro y con la ayuda de una cazuela rota: arrodilladas en el suelo, sujetan la pieza con una mano, mientras que con la otra vierten la envuelta.

\subsubsection{Proceso de cocción.}

El horno es propiedad particular de los artesanos y en ocasiones lo alquilan a otros (tareeros) que no disponen de él.

El combustible utilizado es madera local seca (urces y jara) y de sección fina, que consigue una llama de gran poder calórico. La combustión bien es recolectada por los alfareros en la cercana sierra de Casas Viejas, bien comprada a los campesinos del valle del Jamuz. Se almacena en la portalina del horno; cobertizo 
erigido en el patio del a casa-taller, muy cerca del horno y que permite aislar la madera de la humedad hasta que se utilice.

La cerámica se cuece en los hornos de tiro superior o hispano-moriscos, inspirados en modelos islámicos y que estuvieron en uso en gran parte de Europa a lo largo de la Edad Media. La madera se quema en el hogar o caldera situado en la parte inferior y las llamas alcanzan la cámara superior o de cocción a través de los ojales (agujeros) practicados en el centro y laterales de la superficie que separa ambas cámaras. Una chimenea en la parte superior se utiliza como salida de humos ${ }^{12}$.

En nuestro caso, el horno se erige en el patio de la casa-taller, estructura de planta rectangular limitada con muros de adobe, recubiertos al interior con una capa de arcilla. En la parte inferior del horno diferenciamos dos espacios: el hogar o caldera donde se coloca el combustible y la cámara de cocción donde se depositan las piezas. La caldera mide aproximadamente 1 metro de alto, está separada de la cámara de cocción por la planta o suelo del horno, que a su vez descansa sobre una arcada triple construida en adobe. El combustible se introduce a través de un vano abierto en uno de los lados del horno.

La cámara de cocción, de planta cuadrangular, una altura de 2,20 metros y 1,20 de ancho, presenta distintas partes: el suelo del horno, de 15 centímetros de espesor y fabricado en adobe, consta de 15 ojales cilíndricos, de 5 centímetros de radio, cruzando de forma vertical la cámara de cocción, que posibilita que el calor se traspase de la caldera a la cámara. En cada ojal se coloca un caño vertical, fabricado en teja. En la boca o puerta del horno, de 1,80 metros de alto y 0,40 centímetros de ancho, se sitúa uno de los 15 ojales. Concluido el proceso de carga (hornada), la puerta del horno se cierra con un muro de adobe, teja y arcilla construido al efecto y una vez finalizada la cocción se procede a su derribo.

El horno se techa con la cimbra o capita; estructura abovedada construida para albergar cuatro ojales con forma cuadrangulares, de 20 centímetros de lado, que permiten la salida de humo, gases y llamas, a la vez que sirven para controlar visualmente la cocción.

En ocasiones, una vez que ha concluido la cocción, los ojales de la capita son tapados con teja, así se pretende mantener parte de la temperatura interior del horno hasta la siguiente hornada.

${ }^{12}$ RHODES, H. (2004). Hornos para ceramistas. Barcelona, p. 57-67. 
Antes de comenzar la cargar el horno (hornada), el alfarero retira del hogar las cenizas que pudieran quedar de las cocciones anteriores. En la hornada las piezas se introducen por la puerta del horno, y se disponen unas sobre otras formando círculos concéntricos (llevar la hila) hasta llegar a la capita; se empieza por las cerámicas de mayores dimensiones y sin vedrío, puesto que son las más fáciles de introducir el la cámara de cocción, y sobre ellas se disponen las piezas más pequeñas y las barnizadas. Una vez hecha la carga, la puerta se sella con adobe, teja y barro.

La cámara de combustión se llena por abertura lateral de la que dispone, por donde se va echando la madera seca a medida que la necesita y con la ayuda de una pala metálica o tornadera. Concluida la carga, se procede al encendido del horno. El templado dura unas tres horas, alcanzando una temperatura de $200^{\circ} \mathrm{C}$. Durante esta fase las piezas aumentan progresivamente de temperatura, y terminan de perder la humedad que aún conservan tras el segundo secado. La segunda etapa dura unas dos horas y la temperatura se incrementa hasta llegar a los 500-600 ${ }^{\circ} \mathrm{C}$. La tercera fase tiene lugar a lo largo de las tres siguientes horas: la temperatura alcanzada es de $900-950^{\circ} \mathrm{C}$. En la última etapa se mantiene la misma temperatura durante un par de horas más: las llamas cruzan la cámara de combustión y la cámara de cocción hasta la capita y salen por los cuatro ojales.

El alfarero comprueba el estado de la carga observando el interior de la cámara del horno a través de los ojales de la bóveda, ayudado por una escalera de mano. Además realiza muestras o pruebas de cocción: coloca una cerámica en uno de los ojales de la bóveda, y después de unas horas de cocción, se extrae la pieza con la ayuda de un gancho de hierro.

Terminada la cocción, se deja enfriar el horno antes de abrir la boca o puerta del horno, procurando que el descenso de la temperatura interior se produzca de forma pausada.

La operación de retirar la cerámica cocida del horno se denomina deshornar y comienza cinco horas después de haber terminado la cocción. Previamente al deshornado, el alfarero comienza a derribar la puerta de la cámara de cocción o boca del horno con lo que pierde parte del calor acumulado aún en el interior; unas tres horas después se extraen las piezas por donde fueron introducidas.

Tras ser sacados del horno, los recipientes son extendidos en el corral de la casa-taller, donde se procede a su contabilización. El conjunto cerámico, preparado para la comercialización y agrupado por tipos, se deposita un una pequeña estancia ubicada en el patio y cercana al horno (casa afuera). 


\section{PRODUCCIÓN Y COMERCIALIZACIÓN.}

En cuanto a la producción, la mayoría de alfareros trabajan sobre encargos previos de los compradores, que concretan tanto la morfología y capacidad de los recipientes como el plazo de entrega.

El coste de la cerámica se marca en función del precio de las materias primas utilizadas en la combustión y ornamentación. La madera se adquiere por compra en el propio pueblo, donde todos los días llegan campesinos de la comarca de Valdejamuz con urces y jara fina. Un intermediario local proporciona los materiales utilizados en la decoración: el alcohol de hoja procede de las minas de galena existentes en Linares (Jaén), mientras que el óxido de calcio se consigue de la abundante piedra caliza hallada en el cercano municipio de Quintana y Congosto.

Las piezas se contabilizan por docenas y las mayoría de las cerámicas que se comercializan son contenedores de líquidos y alimentos (tinajas, cántaros, orzas, lebrillos, etc), para los que siempre se concreta la capacidad que pueden llegar a albergar.

El cobro se realiza una vez que el cliente ha recibido y comprobado que el pedido cumple con las condiciones establecidas previamente en el contrato de compra.

En ocasiones, son los propios alfareros los que se encargan de la venta al detalle, en otros casos la transacción se efectúa por diferentes localidades transportando las piezas en carros tirados por animales de carga, o en ferias celebradas en las principales poblaciones.

Las ferias semanales a las que acudían los alfareros eran las de Astorga, La Bañeza, León, Santa María del Páramo, Valencia de Don Juan, Villamañán, etc. La venta de productos cerámicos puede hacerse bien por dinero o bien mediante trueque, a cambio de productos agrícolas o artesanos.

En otros casos, los viajes de los artesanos pueden prolongarse varios días, hasta agotar las piezas que portan, practicando la venta en todas las poblaciones por las que pasan.

\section{TIPOS CERÁMICOS.}

Tipológicamente presentan un vasto repertorio formal, pudiendo hablar de: tinajas, barreños o lebrillos, cántaros, cuencos, cazuelas, fuentes, platos, jarras, jarritas, tazas, potes o botellas, botijos, etc. (Fig. 2). 
Un parte de la producción comprende a tipos dedicados a servicios de mesa y cocina. La forma más numerosa son las jarras y jarrita troncocónica de pasta rojiza, con asa de sección rectangular, borde exvasado y labio redondeado, muchas de ellas con piquera de pellizco, diámetro de boca que varía desde los $4 \mathrm{~cm}$ hasta los $10 \mathrm{~cm}$, entre $3 \mathrm{~cm}$ y $8 \mathrm{~cm}$ en la base y con una decoración de barniz plúmbeo tanto al interior como al exterior.

Tras las jarras se sitúan las fuentes de pasta roja, borde exvasado y labio biselado, diámetro de borde de entre 12 y $20 \mathrm{~cm}$ y de la base entre 8 y $14 \mathrm{~cm}$, además de decoración vidriada.

También cazuelas de pasta roja, biasadas, de borde envasado, labio redondeado, con diámetro de boca de entre 6 y $9 \mathrm{~cm}$, y de entre 5 y 7,5 $\mathrm{cm}$ en la base, con ornamentación de vedrío plúmbeo, cuencos exvasados de pasta roja, diámetro de boca de $8-11 \mathrm{~cm}$ y en cuya ornamentación se combina el vidriado con las pinceladas de cal formando ondulaciones; platos de pasta rojiza, borde exvasado, labio redondeado, con un diámetro de boca de 8 a $12 \mathrm{~cm}$, y en la base de 7 a $10 \mathrm{~cm}$, con decoración vidriada y moldura próxima al borde.

Además de las producciones de mesa y cocina, se encuentra un gran porcentaje de cerámica de almacenamiento (cántaros, lebrillo o barreños, botijos), entre las que la decoración se logra mediante la aplicación de cordones con impresiones digitales.

Los cántaros, muestran perfiles globulares, bordes envasado, labios redondeados o biselados y cuellos rectos. Los de mayor tamaño, presentan diámetros de boca de entre 14-16 cm en la base de 10-14 cm, mientras que en los más pequeños se reducen hasta los $10-11 \mathrm{~cm}$ en la boca y $10 \mathrm{~s} 7-9 \mathrm{~cm}$ en la base. Una gran parte se decoran con impresiones digitales.

Los lebrillos o barreños presentan pastas rojizas e inclusiones de cuarzo y mica, borde exvasado, labios redondeado o biselados. El tipo de ornamentación más habitual es el vedrío interior y exterior; la aplicación de cordones con impresiones digitales son el segundo motivo en importancia. Los diámetros varían entre los 42$60 \mathrm{~cm}$ de la boca y los $28-48 \mathrm{~cm}$ de la base.

Junto a estos, los botijos de cuerpos globulares, asas de sección rectangular, picos vertedores, con diámetros de base de entre 12 y $15 \mathrm{~cm}$ y sin decorar.

Como indicamos, otro de los tipos que se incluye dentro las cerámicas de almacenamiento son las tinajas: en su mayoría presentan pastas ocre con abundantes inclusiones de mica y cuarzo, de cocción oxidante, con el borde 
envasado, labio redondeado y decoradas con marcas de digitación, cuellos cóncavo y diámetros de $35 \mathrm{~cm}$ en la boca y $52 \mathrm{~cm}$ en la base. En todos los casos los encontramos decorados con aplicaciones de cordón con impresiones digitales y en ocasiones el labio también presenta ornamentación a base de digitaciones.

\section{ORGANIZACIÓN DEL ESPACIO.}

El estudio de la documentación y las labores de campo nos permiten conocer de forma pormenorizada la distribución de instalaciones y los métodos de trabajo de este artesanado.

Centrándonos en la organización del espacio en el que se desarrolla la actividad alfarera, proponemos una definición de la casa-taller y sus principales componentes arquitectónicos: por una parte la descripción y utilidad de las diferentes estancias, por otra los materiales constructivos.

\subsection{La casa-taller.}

En la reconstrucción de los espacios de labor y domésticos podemos llegar a diferenciar una serie de elementos arquitectónicos elementales existentes en este hábitat rural artesano como son: los tendales, el patio o corral, la toña, el obrador, la portalina del horno, el horno, el pozo y la casa afuera (Fig. 3).

La casa taller, rodeada de muros de tapial, se organiza en torno a un gran patio o corral de dimensiones variables. El uso que se le da está relacionado con el desempeño del oficio alfarero y se utiliza como zona de paso entre las diferentes estancias de la casa-taller. Esta cuenta con una sola planta dado que, como es lógico, resulta mucho más cómodo para el desarrollo de la actividad alfarera.

Los tendales se sitúan en una esquina del patio o corral, próxima a la toña o sala de almacenamiento de la arcilla seca, y presenta dimensiones variables. Se trata de una superficie de arcilla pisada dedicada a desbrozar y orear el barro recién traída del barrero.

La toña o habitación de almacenaje del barro se ubica al lado del obrador y está destinada a albergar la arcilla recogida en el yacimiento y oreada, donde se deposita hasta el momento en el que se use. Esta estancia tiene planta rectangular, de 5 metros de longitud y 3 metros de anchura.

El obrador es el lugar donde se desarrolla la actividad artesanal, con una extensión variable, pero que habitualmente presenta una planta rectangular, de unos 5 metros de longitud y 10 de ancho. El sistema de cierre suele ser mediante un tejado a dos aguas. Dentro alberga diferentes herramientas del oficio alfarero: la 
rueda se coloca en uno de los laterales de la habitación y adosada a la pared; en otro lado, y comunicada con la toña, se encuentra la barrera, utilizada para sumergir la arcilla seca en agua antes del sobado o amasado, se trata de una estancia de forma rectangular de $80 \times 60$ centímetros de ancho y 1 metro de largo; muy cerca de la rueda el banco de sobar, mesa de madera de roble con cuatro patas, forma rectangular y escasa altura, donde se malea la masa de arcilla antes de su torneado; los chisperos o vigas de madera, de 2 metros de largo, en las que se disponen las tablas de oficio hasta finalizar en primer secado de las piezas; por último, el hogar, que proporciona un temperatura agradable en el obrador, al tiempo que funciona como espacio de secado improvisado en los momentos en los que el clima no permite hacerlo en el patio (Fig. 4).

La portalina del horno o cobertizo funciona como lugar de almacenamiento de la madera, donde se protege de las inclemencias del tiempo, además de albergar los recipientes con defectos de cocción.

El horno se erige en el centro del corral; se trata de una estancia de planta rectangular y cierre con en bóveda de cañón, construida íntegramente en adobe y con cubierta de teja.

El pozo se ubica próximo al obrador, de donde se extrae el agua necesaria tanto para la preparación de la pasta cerámica como para las labores domésticas.

La casa afuera, sin localización fija, se utiliza para el almacenamiento del material cerámico resultante de la cocción.

\subsection{Materiales constructivos.}

Los muros de tapial que cercan el perímetro de la casa-taller se fabrican con tierra local y pequeños cantos rodados.

Las diferentes estancias que conforma la casa-taller son construidas por los alfareros, auxiliados por los aprendices. El material constructivo más empleado en las construcciones de Jiménez de Jamuz es el adobe, realizado con arcilla y paja local secada al sol, utilizado tanto en el alzado de las paredes como en la fabricación de suelos y techumbres. Los muros tienen aproximadamente 30 centímetros de grosor y más de 2 metros de alto. El tipo de planta que predomina en estas habitaciones es rectangular, salvo en el horno, de forma cuadrangular, en tanto que el sistema de cierre más utilizado es el tejado a dos aguas ${ }^{13}$.

${ }^{13}$ Alonso PongA, J. L. (1994): La arquitectura del barro. León. 
Otro de los materiales que se usa es la madera de roble procedente del cercano Monte de la Casa, que incluye toda la carpintería de la construcción (postes, vigas, techumbres) y las herramientas del oficio de alfarero (batedera, banco de sobar, cabezuelas, rueda, chisperos, recorteador, punta de embocar, etc.).

El uso de la piedra autóctona se limita exclusivamente al alzado de la caldera o cámara inferior del horno y los zócalos de 40 centímetros sobre los que se erigen las paredes.

Además de vigas de madera, en el sistema de cierre, con cubiertas a dos aguas, se emplea adobe y teja. Por último, la teja se adquiere en los cercanos municipios de Quintana y Congosto y Santa Elena de Jamuz (Fig. 5).

\section{CONSIDERACIONES FINALES.}

El repaso a las fuentes documentales y el trabajo de campo permite poner en valor las posibilidades que ambas ofrecen para el estudio de la producción cerámica.

Este trabajo está centrado en un núcleo rural como es Jiménez de Jamuz, dedicado tradicionalmente a la fabricación de cerámica, y orientado hacia los aspectos tanto técnicos, morfológicos y decorativos como sociales y económicos.

La producción cerámica de Jiménez de Jamuz conlleva la presencia de una serie de estancias, el uso de útiles específicos para el modelado y la ornamentación y una preparación propia de la materia prima, que nos proporciona evidencias para conocer mejor todo el proceso de fabricación.

Una parte de este proceso tecnológico tiene una aplicación etno-arqueológica. El registro arqueológico permite conocer ciertos aspectos de carácter tipológico, funcional, etc, mientras que este tipo de estudio ofrece la posibilidad de conocer otros aspectos fundamentales como la obtención y tratamiento de la arcilla, el aprovisionamiento del combustible, la organización de las diferentes estancias vinculadas a este oficio y los materiales de construcción utilizados en ellas, las técnicas de fabricación y los aperos usados durante el proceso de elaboración que en casos muy contados dejan restos en el registro arqueológico.

Además ofrece la posibilidad tanto de establecer determinados aspectos de carácter arqueológico e histórico desconocidos hasta el momento como plantear si existe relación entre las técnicas de fabricación contemporáneas y las producciones de cerámica más antiguas documentadas en determinados registros arqueológicos. 
Así mismo, la información proporcionada por este tipo de examen nos permite llegar a conocer los procesos tecnológicos y la distribución del espacio doméstico y de labor en centros coetáneos al estudiado.

\section{ABREVIATURAS.}
A.H.P.L. Archivo Histórico Provincial de León.
B.R.H. Biblioteca de la Real Academia de la Historia.

\section{GLOSARIO.}

Amasado o sobado: proceso de preparación de la arcilla antes del torneado. Se realiza golpeando repetidamente con los puños la masa contra la mesa, cortándola en trozos que vuelven a unirse por presión. Simultáneamente se procede a quitar todo tipo de impurezas que puedan quedar en la pasta.

Banco o mesa de sobar: mesa fabricada con madera de roble donde se malea la mase de arcilla antes de su modelado.

Bañar las piezas: aplicación del barniz vidriado a la cerámica momentos antes de la cocción.

Barrera: estructura con forma rectangular y de reducidas dimensiones utilizada para la inmersión de la pasta antes del amasado.

Barreros: yacimiento de arcilla a cielo abierto localizado en las proximidades de la población leonesa de Jiménez de Jamuz y propiedad de los alfareros del municipio.

Batedera: pala de madera con la que se remueve la arcilla después de haber estado durante cierto tiempo inmersa en agua.

Boca del horno: puerta frontal de la cámara de cocción, de unos $40 \mathrm{~cm}$. de ancho y $1,80 \mathrm{~cm}$. de alto, a través del a que se introduce el material cerámico en la cámara de cocción. Una vez llena la carga, esta puerta es sellada con adobes y, concluida la cocción, se procede a su derribo.

Bolo: cada una de las cantidades de arcilla empleadas por el artesano para realizar un recipiente a torno rápido.

Casa-afuera: habitación localizada en el patio de la casa-taller, donde se almacena la vajilla lista para la venta. 
Cabezuela: placa circular de madera de roble que se coloca sobre el disco superior del torno para modelar piezas de gran tamaño.

Cámara superior o de cocción: estructura cuadrangular, con una altura de unos 2,20 metros y 1,50 de lado, situada sobre la caldera y en la que se coloca la cerámica para la cocción. La carga del a cámara se hace a través de una puerta frontal que, una vez hecha la carga, es tapiada con adobe.

Capita o cimbra: estructura abovedada que cierra la cámara de cocción. Esta cuenta con cuatro caños cuadrangulares, de 20 centímetros de lado, que tienen como función permitir la salida de gases, llamas y humos del interior, además de servir como medio de control visual.

Casa-taller: espacio de labor y doméstico en torno al que se organiza la vida de los alfareros del municipio de Jiménez de Jamuz.

Chisperos: vigas de madera, de aproximadamente 2 metros de longitud, en las que se depositan las tablas de oficio hasta concluir el secado parcial de la vajilla.

Cocina-obrador: estructura de habitación de planta rectangular dentro de la cual se albergan parte de las herramientas utilizadas en el oficio alfarero.

Deshornar: proceso a través del cual, concluida la cocción, se procede a vaciar el contenido del horno.

Dureza del cuero: secado parcial del a arcilla, que permite su manipulación sin que se deforme.

Enasado: acción mediante la cual se procede a colocar asa al recipiente que lo requiera.

Hogar o caldera: parte inferior del horno donde se deposita el combustible. La caldera tenía una altura de poco más de un metro y está separada de la zona de cocción por un suelo; la carga del combustible en la caldera se hace a través de un vano abierto en uno de sus laterales.

Hoja de alcohol: barniz de baja temperatura, con un componente fundamental, el Sulfuro de Plomo que los alfareros denominaban alcohol de hoja, procedente de las minas de galena que existían en Linares (Jaén).

Hornar: operación mediante la cual se colocar la cerámica en el horno de cocción. 
Horno de tiro superior o hispano-morisco: horno de planta cuadrangular, construido íntegramente en adobe y que se caracteriza por separar la cámara de cocción de la de combustión. El combustible se quema en el hogar de la parte inferior y las llamas llegan a la cámara de cocción a través de los agujeros presentes en el centro y en cada uno de los lados del suelo de la cámara. La salida de humo y gases se sitúa, a modo de chimenea, en la parte superior.

Llevar la hila: las piezas se apilan unas sobre otras formando anillos concéntricos hasta llegar a la bóveda; se comienza por los recipientes de mayor tamaño y carentes de barniz, pues y sobre ellas se coloca la cerámica de menor tamaño y las vidriadas.

Muestra: el alfarero realiza una prueba de cocción en cada carga del horno, colocando una cerámica en los ojales de la bóveda, y transcurridas unas horas de cocción procede a extraer la pieza a través de uno de ellos ayudado por un gancho de hierro.

Ojales: agujeros circulares situados en la planta del horno, de $10 \mathrm{~cm}$. de diámetro, que atraviesan verticalmente la zona de cocción, permitiendo que el calor pase de la caldera a la cámara.

Pieza de cuero o tiradera: pequeño trozo de cuero con el que el alfarero suaviza la superficie del recipiente.

Pella: volumen reducido de arcilla de forma troncocónica que se deposita junto al torno del alfarero donde se deja reposar unos días antes de ser utilizada.

Portalina del horno: cobertizo en el que se almacena el combustible utilizado en el horno de cocción.

Punta de embocar: fragmento de madera con uno de los extremos terminado en punta usado para practicar decoraciones incisas.

Ralillas: arcilla sobrante del torneado, caracterizada por su gran plasticidad y utilizada para fabricar las asas, picos y vertederas.

Rebabas: restos de arcilla que quedan en el recipiente tras tornedo y se eliminan con el recorteador.

Reblo: nivel estéril de tierra de un metro de altura que se sitúa sobre la arcilla.

Recorteador: espátula de madera utilizada para eliminar las rebabas que pueden haber quedado del torneado y perfilar las bases al exterior. 
Repasar la pieza: acción de eliminar las rebabas o restos de barro que puedan haber quedado del torneado y se perfila sobre todo la base con un espátula de madera.

Rueda: torno de alfarero fabricado íntegramente en madera de roble y constituido por dos discos horizontales paralelos unidos por un eje perpendicular enterrado en el suelo que pasa por el centro de éstos.

Suelo o planta del horno: estructura de unos $15 \mathrm{~cm}$. de grosor y construida íntegramente en adobe, que separa la caldera de la cámara de cocción.

Tablas de oficio: tablas de madera de roble de entre 2 y $2,5 \mathrm{~m}$. de longitud y 30 $\mathrm{cm}$. de ancho que se disponen en la mesa del torno y sirven para transportar las piezas al lugar de secado.

Tareeros: alfareros ocasionales que frecuentemente carecen de horno y a los que se solía pagar un jornal por la fabricación de una cantidad concreta de material cerámico.

Tendales: superficie plana donde se desbroza, allana y limpia la arcilla. Se ubicada bien en la zona de extracción de la arcilla bien en el patio de la casa-taller.

Toña: habitación destinada a almacenar la arcilla una vez oreada, donde permanece hasta el momento de ser usada.

Tornadera: pala metálica con la que se ayuda en alfarero para echar el combustible al horno. 


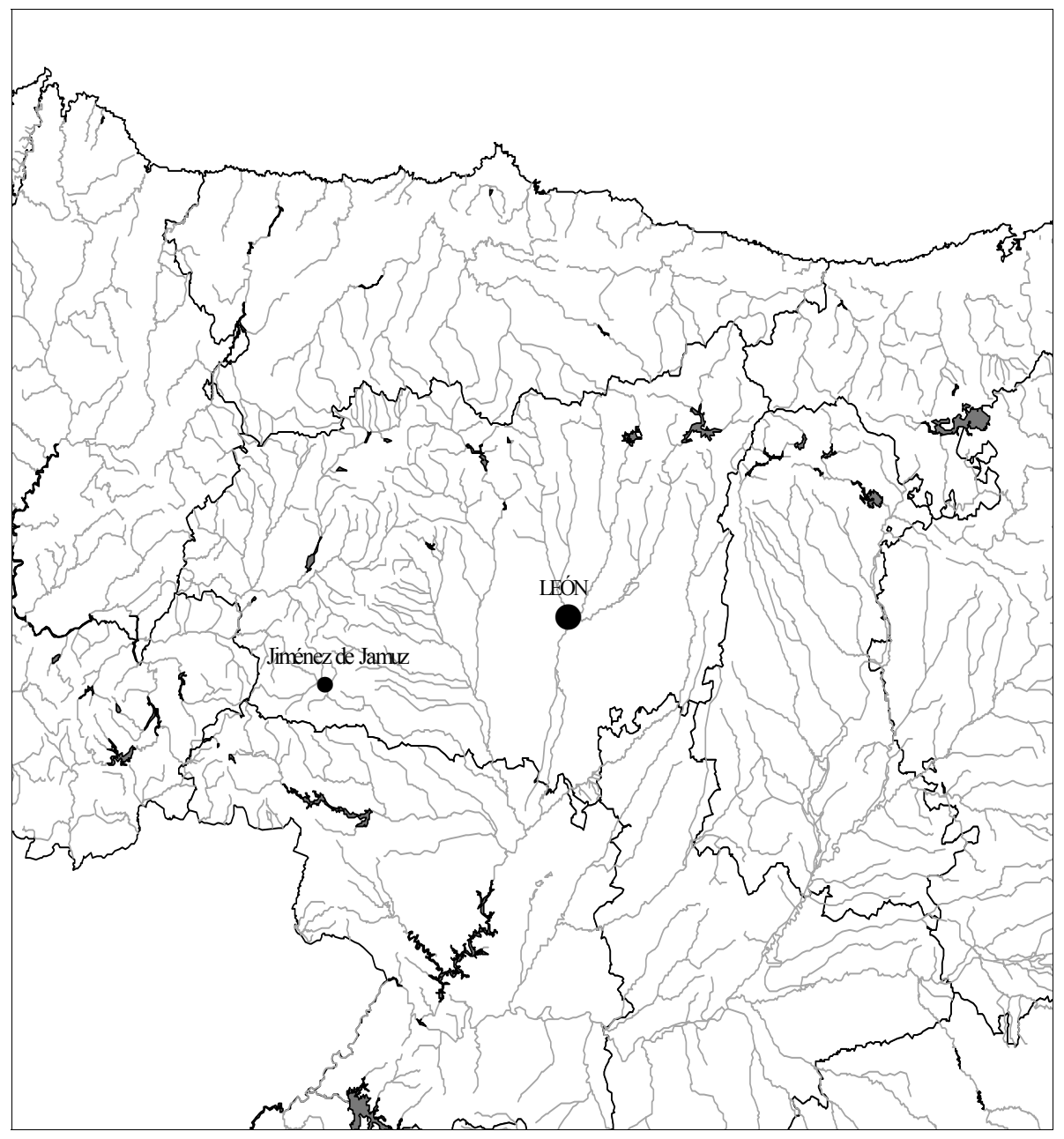

Fig. 1: Localización de Jiménez de Jamuz (León). 

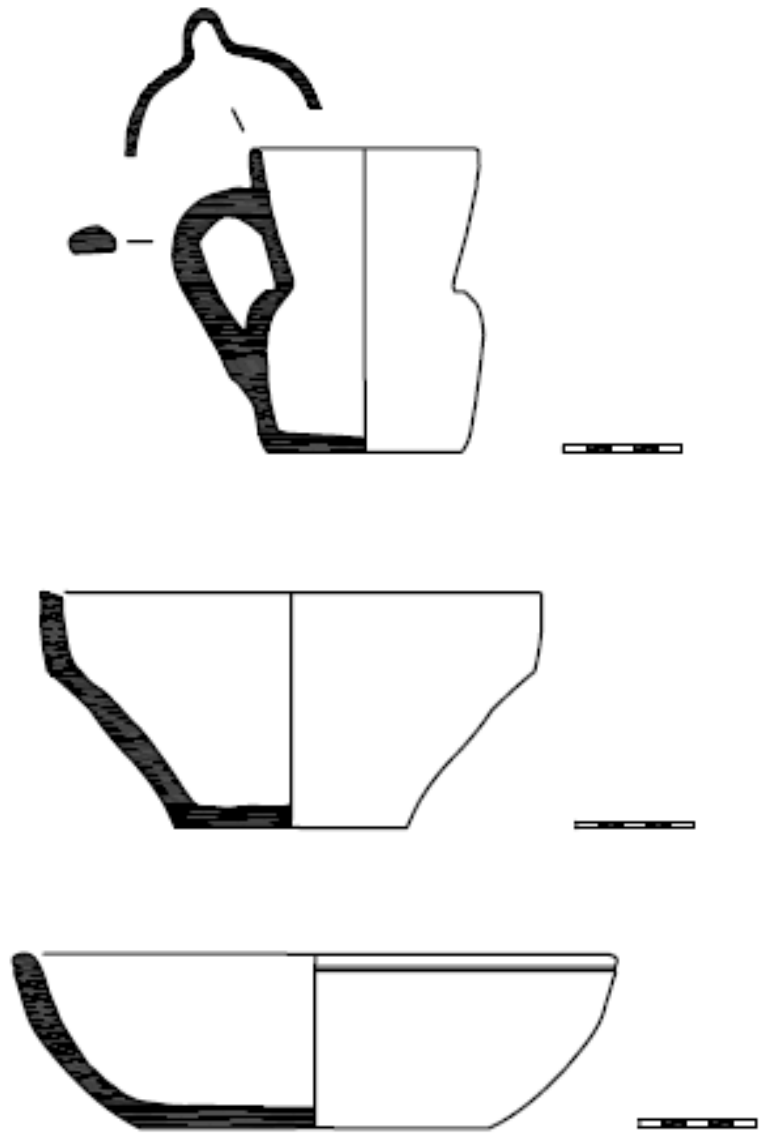

Fig. 2: Material cerámico. 


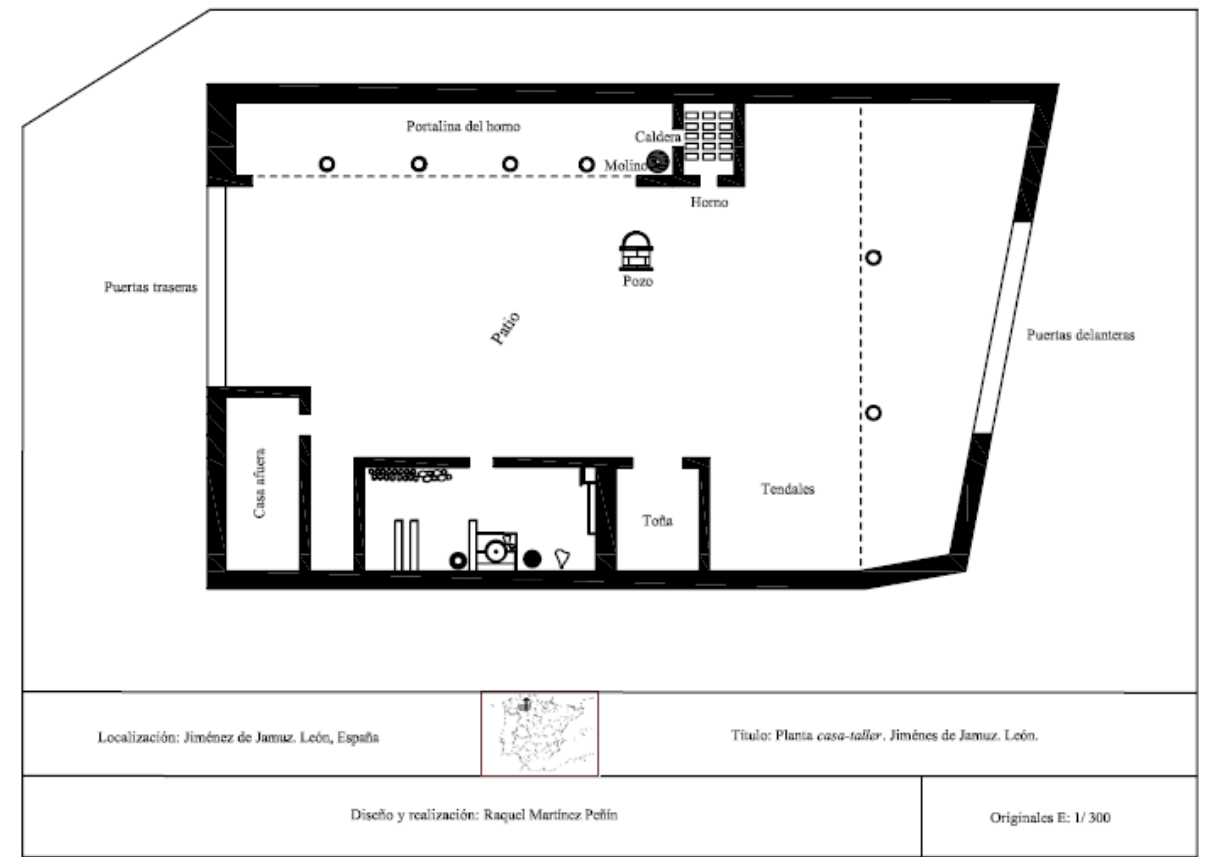

Fig. 3: Ejemplo de casa-taller, Jiménez de Jamuz.

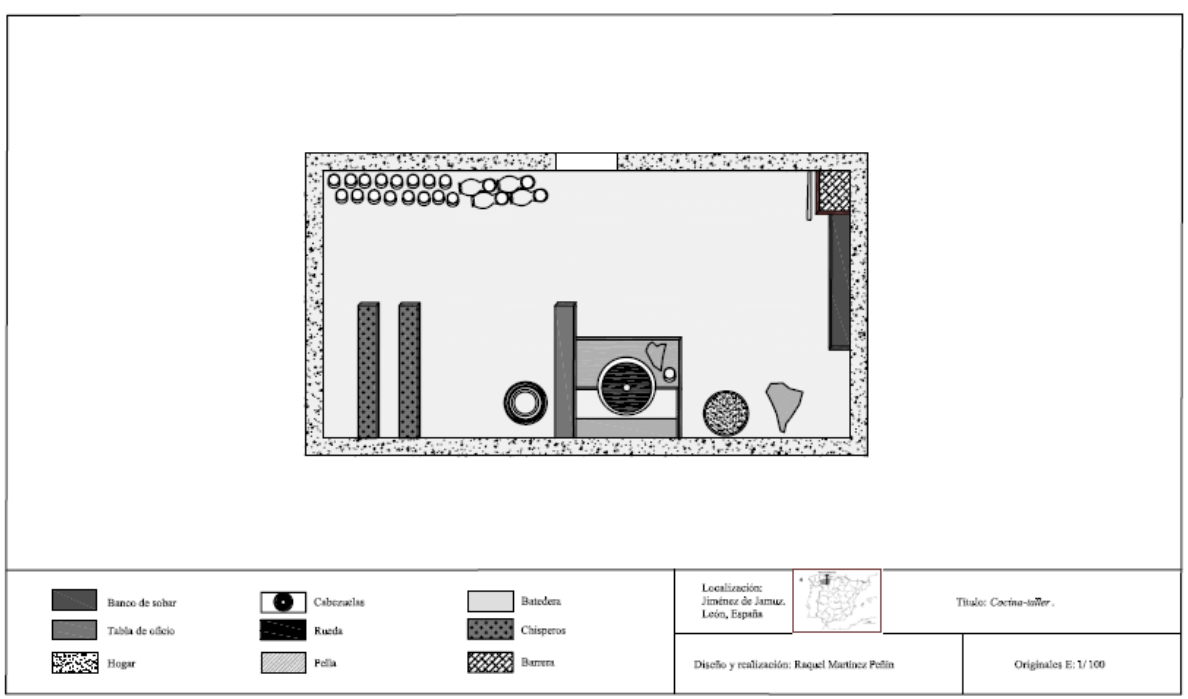

Fig. 4: Plano de cocina-taller. 
Alexandra Rodera Alonso

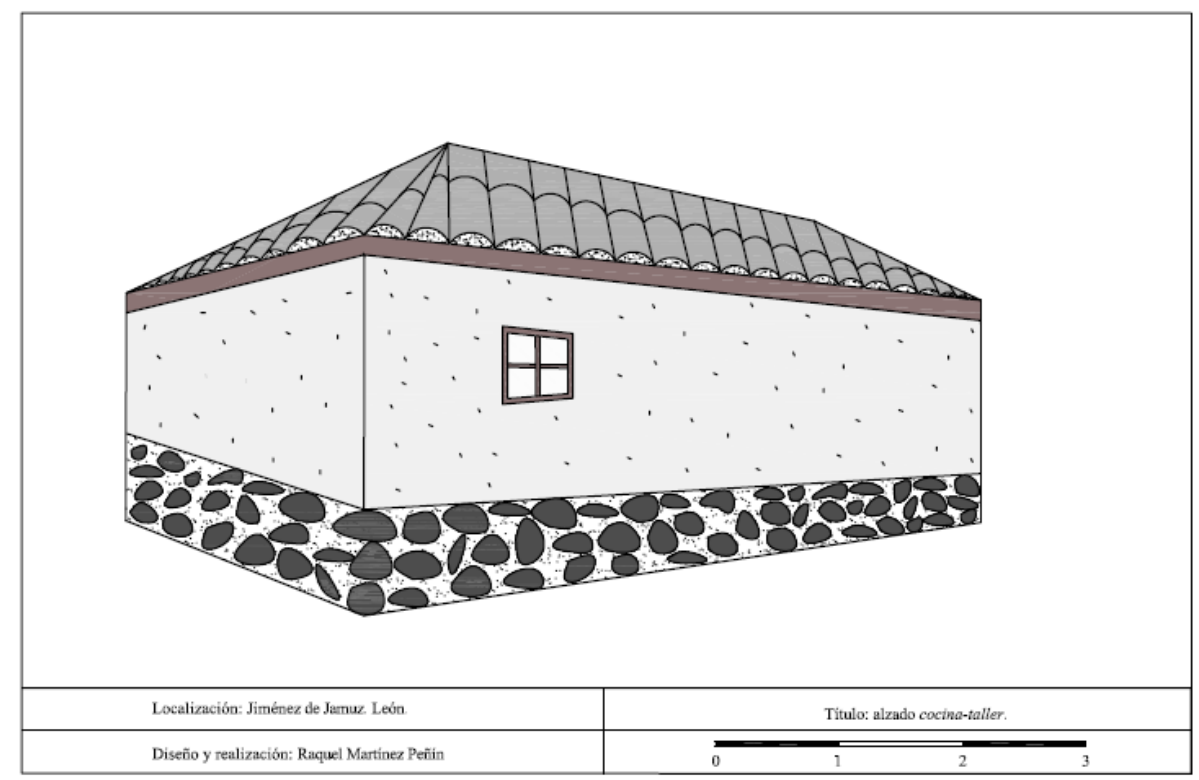

Fig. 5: Alzado de cocina-taller. 
Sección III: Reseñas Bibliográficas 
